\title{
Therapeutic Strategies in Dental Origin Mediastinitis: Cases Report
}

\author{
Socha Agnieszka, Niedzielska Iwona and Lyko-Morawska Dorota*
}

Department of Cranio-Maxillo-Facial and Oral Surgery, School of Medicine, Division of Dentistry, Zabrze, Medical University of Silesia, Katowice, Poland

*Corresponding author: Dorota Lyko-Morawska, Department of Cranio-Maxillo-Facial and Oral Surgery, School of Medicine with the Division of Dentistry in Zabrze, Medical University of Silesia, Katowice, Ul: Francuska 20-24, 40-027 Katowice, Poland, Tel: 32-2518361, E-mail: dorota.lyko@gmail.com

\begin{abstract}
Descending Necrotizing Mediastinitis (DNM) can be dangerous complication after infection in the head and neck region. In spite of possibilities of using wide range of antibiotics, with isolated DNM, mortality approaches $40-50 \%$, and when associated with comorbidities, rates as high as $80 \%$ has been reported respectively. In head and neck region one of the most frequent cause of the inflammatory process are teeth and tonsils. The aim of this article is to draw attention to the problem of life threatening complication of odontogenic and other inflammatory disorders among facial parts of the skull. We present the development of inflammatory disorders resulting from odontogenic and pharyngeal infections to Descending Necrotizing Mediastinitis (DNM) and the new method of treatment using vacuum therapy.
\end{abstract}

\section{Keywords}

Inflammatory disorders, Descending necrotizing mediastinitis, DNM, SIRS, DIC, Vacuum therapy

\section{Introduction}

At the time of widely developed medical knowledge, access to a broad spectrum of antibiotics and medical equipment, are we protected from complications including death due to the spread of aggressive inflammation. Are complications of inflammatory head and neck infections easily curable?

Most oropharyngeal and oral cavity infections are self-limiting and contained [1], however, in some cases can cause one of serious and life-threatening disorderDescending Necrotizing Mediastinitis (DNM) [2]. DNM is a rapidly progressive disease which spread toward the mediastinum along the deep cervical fascia further by negative intrathoracic pressure during respiration and by gravity [3]. This is predominantly a disease of young men (between 35-45 years old), where the male to female ratio is approximately 6:1 [4]. (1) In 1983 Estrera defined the DNM diagnosis criterions, including the clinical and radiological symptoms: Clinical manifestations of severe infection; (2) Demonstration of characteristic radiographic findings; (3) Documentation of necrotizing mediastinal infection in operation; and (4) Establishment of oropharyngeal/cervical infection with descending necrotizing mediastinitis relationship. Early recognition and surgical treatment are important as this disease is associated with high mortality rate between 19 to $47 \%[1,2]$, cause by sepsis and organic failure if not treated quickly and properly [5]. Authors present three cases of DNM from odontogenic and oropharyngeal source, who were hospitalized between 2001 to 2013 in the Department of Cranio-Maxillo-Facial and Oral Surgery.

\section{Cases}

\section{Case 1}

A 20-years-old man with past medical history significant for haematological disorders (lymphoblastic acute leukemia; 9 years before treated by chemotherapy), was admitted to the Cranio-Maxillo-Facial Department during the night duty, with two-days history of increasing right neck swelling and increasing throat pain. The right submandibular site abscess was diagnosed. Extraction of tooth 36 was done previously in dentistry practice. Patient denied upper respiratory tract infection or history of similar symptoms. During clinical examination, the patient was noted to have induration of

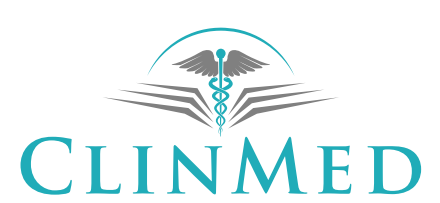

INTERNATIONAL LIBRARY
Citation: Agnieszka S, Iwona N, Lyko-Morawska D (2017) Therapeutic Strategies in Dental Origin Mediastinitis: Cases Report. Int J Oral Dent Health 3:046. doi.org/10.23937/2469-5734/1510046 Received: October 24, 2016: Accepted: August 19, 2017: Published: August 21, 2017

Copyright: (c) 2017 Agnieszka S, et al. This is an open-access article distributed under the terms of the Creative Commons Attribution License, which permits unrestricted use, distribution, and reproduction in any medium, provided the original author and source are credited. 
Table 1: Laboratory results from the day of admission to the stay on the ward to the discharge day.

\begin{tabular}{|c|c|c|c|c|c|c|c|}
\hline & Admission day & $\begin{array}{l}2 \text { days after } \\
\text { admission }\end{array}$ & $\begin{array}{l}4 \text { days after } \\
\text { admission }\end{array}$ & $\begin{array}{l}7 \text { days after } \\
\text { admission }\end{array}$ & $\begin{array}{l}9 \text { days after } \\
\text { admission }\end{array}$ & $\begin{array}{l}18 \text { days after } \\
\text { admission }\end{array}$ & Standards \\
\hline $\begin{array}{l}\text { Body temperature } \\
\left({ }^{\circ} \mathrm{C}\right)\end{array}$ & $39 \uparrow \downarrow$ & $36.4 \downarrow$ & $38.3 \uparrow$ & $37.5 \uparrow$ & $37.9 \uparrow$ & $36.7 \uparrow$ & 36.6 \\
\hline Leukocytosis (/ml) & $16000 \uparrow$ & - & $1800 \uparrow$ & $14700 \uparrow$ & $13100 \uparrow$ & $5500 \uparrow$ & $4000-10000$ \\
\hline INR & 1.21 & 1.2 & $1.47 \uparrow$ & $1.42 \uparrow$ & $1.41 \uparrow$ & 1.09 & $0.92-1.3$ \\
\hline Prothrombin (\%) & $73 \downarrow$ & $74 \downarrow$ & $55 \downarrow$ & $59 \downarrow$ & $59 \downarrow$ & 86 & $78-120$ \\
\hline Fibrinogen (g/dl) & $8.28 \uparrow$ & $7.52 \uparrow$ & $7.72 \uparrow$ & 4.67 & - & 3.19 & $2.20-4.96$ \\
\hline D-dimer (ng/ml) & - & $822 \uparrow$ & $2199 \uparrow$ & $1910 \uparrow$ & $1563 \uparrow$ & $885 \uparrow$ & 500 \\
\hline PT (s) & 13.5 & 13.4 & $16.3 \uparrow$ & $15.7 \uparrow$ & $15.6 \uparrow$ & 12.2 & $10.5-14.4$ \\
\hline APTT (s) & 29 & 32 & 27 & 33 & 34 & 31 & $24-35$ \\
\hline
\end{tabular}

left submandibular region, with erythema tracking from the superior border of mandible to submandible region, vesicular lung sounds and $12 /$ minute breath frequency. Oral examination was remarkable for oedema of buccal area and II otrismus. The $x$-rays were done (mandible posterior-anterior $\mathrm{x}$-ray and oblique $\mathrm{x}$-ray of mandible left and right) (Table 1).

In local anaesthesia the right neck was explored (submandible $2 \mathrm{~cm}$ incision) and extraoral abscess drainage was performed. Intravenous Penicillin with Clavulanic Acid (1.2 g/12 h i.v) with Metronidazol ( $0.5 \mathrm{~g} / 8 \mathrm{~h}$ i.v) was empirically started. Material for bacteriological examination for aerobic and anaerobic bacteria was collected. Two days later in laboratory tests further increase in D-dimer has been noted. Due to no clinical improvement connected with worse laboratory results, the radiological examinations (OPG) was reviewed and the tooth 46 was extracted (negative vital tests connected with big filling). Due to no improvement, the antibiotic was changed to Crystalline Penicillinum. After four days, despite repeated drainage and washout $\left(\mathrm{H}_{2} \mathrm{O}_{2}\right.$, Octenispet - Shulke), the patient began to decompensate, he suffered hectic fever up to $38^{\circ} \mathrm{C}$, the laboratory results continued to rise. On clinical exam, the induration and erythema spread to chin and chick area. Hoarseness in patient's voice was noted. The decision has been made to drain the left submandibular space. In the following days abscesses were drained and rinsed out with peroxide and saline solution. Final wound culture grew Streptococcus anginosus, Enterobacter cloacae, Staphylococcus haemolyticus, Staphylococcus epidermidis, Streptococcus mitis. According to the antibiogram the antibiotic regimen has been changed to Ciprofloxacin and Vancomycin. No fever was noted. Tests for HIV, HCV and HBV have been performed with negative results. On account of crepitus in right paroideus area, in $8^{\text {th }}$ day of hospitalization CT of facial part of the skull and neck has been performed, which revealed extensive phlegmona (Ludwig's Angina) of oral cavity soft tissues, especially at the chin and submandibular area. It also revealed abscess of the right sternocleidomastoid muscle, extend to the level of entry to the larynx, right side of the fossa epiglotica, and end of hyoid bone in the direction of the entry to the thorax. The abscess penetrates the upper thoracic and collateral clavicle, meets directly with the humerus and posterior head on the posterior side. The vertebral abscess is visible on the lower right side of the thyroid cartilage on the right side. The antibiotic treatment was continued. After 17 days of hospitalization in Cranio-Maxillo-Facial Department, due to patient's satisfactory condition the decision has been made to continued treatment in the Hiperbaric Oxygen Centre. Where the total improvement of patient's condition was achieved.

\section{Case 2}

A 63-years-old woman with past medical history for hypertension was admitted to Cranio-Maxillo-Facial Department due to increasing swelling problems after drainage peritonsillar abscess on day before. Cefuroxime and Metronidazole were empirically started. On exam patient was noted neck left side edema and induration. Above lungs normal, vesicular sound, two-sided. Oral examination showed that the bottom of oral cavity has been tenderness and raised in the area of left palatine tonsil, the terminal test in teeth 35,45 showed pulp in gangrenous decomposition. The laboratory showed hypokalemia, increased level of glucose and leukocytes. Patient was immediately taken to the operating room.

Following nasotracheal intubation, the incision, drainage and washout of the right genial and submandibular space have been performed. The tooth 35,45 has been extracted. The empiric antibiotic therapy has been continued. In the following days abscess space has been washout twice a day (hydrogen peroxide). Because the patient was getting worse, the antibiotic has been changed to Crystalline Penicillin and the patient was referred to Otolaryngology Department for consultation, which showed balloon swelling of supraglottis and chorda vocalis. In the fourth day, on the clinical examination the patient was noted to have erythema in upper part of the neck and thorax, reaching $1 \mathrm{~cm}$ beneath clavicle. In local anaesthesia, drainage of neck cellulitis in supraclavicular area on the right and left side has been performed. On the next day patient's condition has improved and in the drain check-up, low level of exudation obtained. In next days, swelling on the neck area has diminished, however in the right mandible space hard oedema sustained.

Final wound culture grew Staphylococcus epider- 
Table 2: Laboratory results from the day of admission to the stay on the ward to the discharge day.

\begin{tabular}{|c|c|c|c|c|}
\hline & Admission day & $5^{\text {th }}$ day & $10^{\text {th }}$ day & Standards \\
\hline Temperature $\left({ }^{\circ} \mathrm{C}\right)$ & $39.4 \uparrow \downarrow$ & $38.9 \uparrow$ & & 36.6 \\
\hline Leukocyte (/ml) & $15340 \uparrow$ & 18590 & $24000 \uparrow$ & $4000-10000$ \\
\hline INR & 1.23 & $1.83 \uparrow$ & & $0.92-1.3$ \\
\hline Prothrombin (\%) & $72 \downarrow$ & $42 \downarrow$ & & $78-120$ \\
\hline Fibrynogen (g/dl) & $5.83 \uparrow$ & 4.81 & & $2.20-4.96$ \\
\hline D-dimer (ng/ml) & - & $5116 \uparrow$ & & 500 \\
\hline PT (s) & $13.70 \uparrow$ & $20.10 \uparrow$ & & $12.5-14.4$ \\
\hline
\end{tabular}

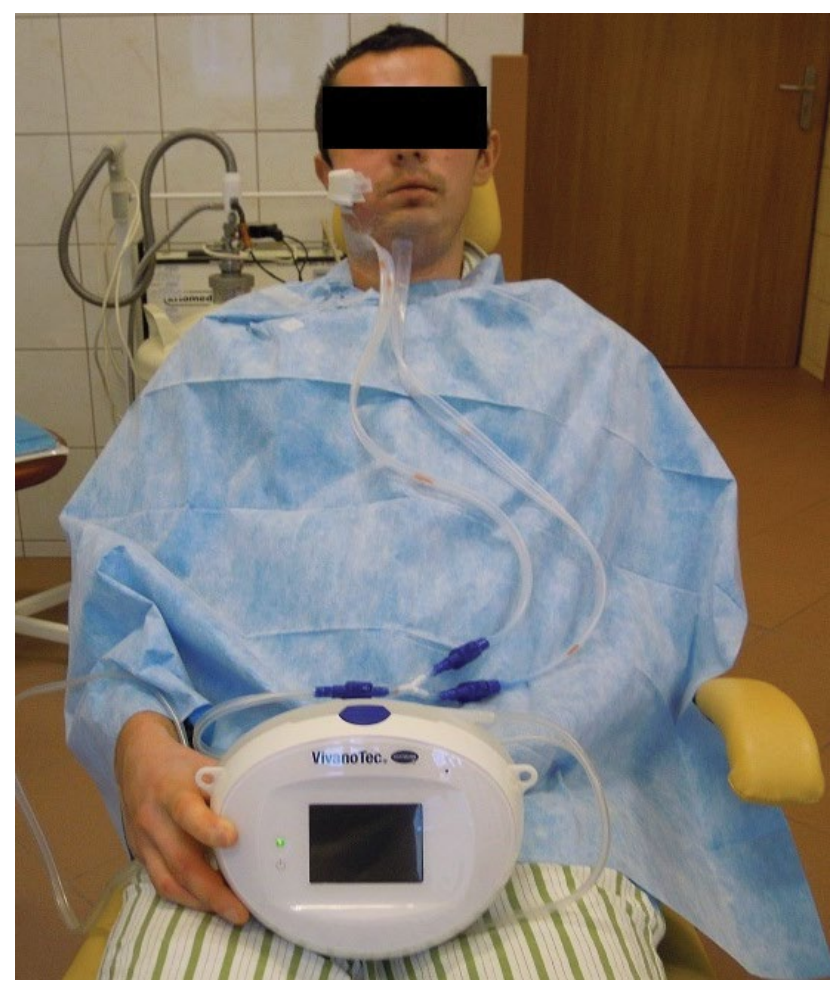

Figure 1: Vivano Tec vacuum therapy after incision, drainage and washout.

midis, Serratia marcescens, Corynebakterium jeikeium. Neck and mediastinum Computer Tomography (CT) was performed, which showed neck cellulitis, mainly on the right side including muscles and neck spaces causing mass effect, spreading to upper part of mediastinum to the level of brachiocephalic vein. Based on the results and clinical examination patient has been referred to the Department of Thoracic Surgery, where further treatment has been performed, which included neck mediastinal drainage and wide spectrum antibiotic treatment. Patient was discharged after 14 days in good general condition.

\section{Case 3}

A 22-year-old man was admitted to the Department of Cranio-Maxillo-Facial Surgery due to neck cellullitis. He was referred by the general practitioner because of increasing neck swelling. 14 days before, he visited a dentist because of tooth 16 ache and swelling in the right submandibular space. Dentist prescribed Doxycykline and suggested a visit after the swelling is gone. Patient with no past medical chronic diseases history. On exam, he was noted to have oedema of the right chick and both submandibular spaces, tracing from the superior border of his angles of the jaw to cricoid cartilage and ${ }^{\circ}$ trismus. Oral examination was remarkable for numerous teeth roots [X-ray]. The laboratory values were significant for elevated leukocyte count, and slight blood clotting abnormalities (Table 2).

On the day of admission, in local anesthesia the extra- and intraoral incision, drainage and washout has been performed with oral cavity sanitation. Vivano Tec vacuum therapy has been used. Penicillin with Clavulanic Acid and Metronidazol were empirically started (Figure 1). Patient received analgesic and febrifugal treatment.

On the third day of hospitalization, patient complained about dry cough without dyspnea. On the fourth day, single rhonchi appeared during lungs examination, HR 100/min, antibiotic has been changed to Ciprofloxacium and Cefuroximum. On the sixth day body temperature dropped to $34.9^{\circ} \mathrm{C}$. On exam, the patient was noted to have weakness of vesicular lung sound on the left side and percussion suppress. Final wound cultures grow: Streptoccocus anginosusu sensitive to Ampicillin, Cefotaxim, Ceftriakson, Vancomycin, Clindamycin and Benzylpenicilin.

Thorax X-ray examination showed: shadowing of the left lung base and left diaphragmatic - costal angle, which may result from liquid in the pleural cavity. In the bottom field of the left lung shown belt-shaped and microfocalis density of probable inflammation character. Widening of mediastinum shadow on the level and above of lung recess which may result from lymphadenopathy or pulmonary infiltrates in mediastinum. Lung recesses widened. Heart silhouette slightly enlarged. Urgent CT scan of the thorax has been performed, which showed; multiple lesions of the abscess character in mediastinum and neck, lesions of atelectasio-infiltratio character in right lung, liquid in both pleural cavities.

Based on the results and clinical examination patient has been referred to the Department of Thoracic Surgery, where was emergently consulted and took to the operation theatre for right side thoracotomy and mediastinum drainage. Patient has been kept in Intensive Care Unit for 6 days (Figure 2), he was discharged from hospital after 20 days of hospitalization.

\section{Disscusion}

The most frequent cause of descending necrotizing mediastinitis used to be odontogenic infection (36\% 


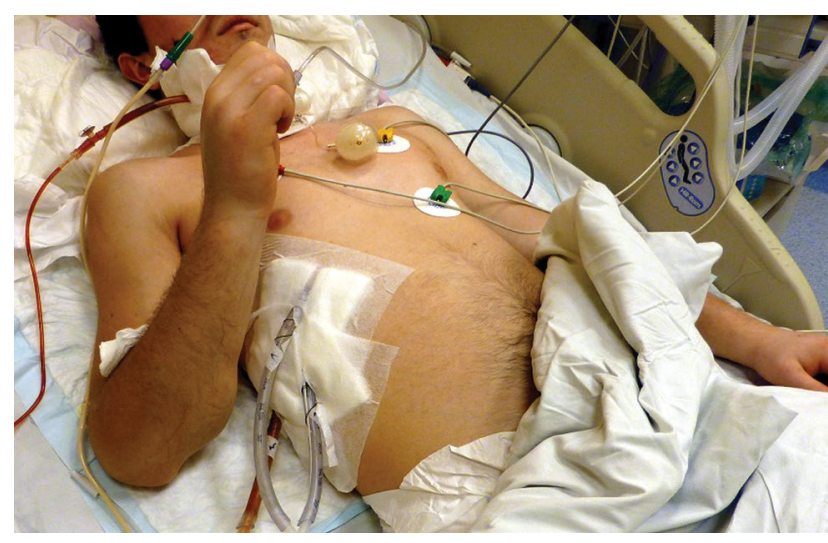

Figure 2: Patient on Intensive Care Unit after incision, drainage and washout of mediastinum.

Table 3: Result of bacteriological culture grow in selected cases.

\begin{tabular}{|l|l|l|}
\hline & Gram-positive bacteria & $\begin{array}{l}\text { Gram-negative } \\
\text { bacteria }\end{array}$ \\
\hline Case 1 & $\begin{array}{l}\text { Streptococcus anginosus, } \\
\text { Staphylococcus epidermidis, } \\
\text { Streptococcus mitis }\end{array}$ & $\begin{array}{l}\text { Enterobacter cloacae } \\
\text { Staphylococcus } \\
\text { haemolyticus }\end{array}$ \\
\hline Case 2 & $\begin{array}{l}\text { Staphylococcus epidermidis, } \\
\text { Corynebacterium jeikeium }\end{array}$ & Serratia marcescens \\
\hline Case 3 & \begin{tabular}{l} 
Streptococcus anginosus \\
\hline
\end{tabular} & \\
\hline
\end{tabular}

to $47 \%$ ) then pharyngeal (33\% to $45 \%$ ), cervical (15\%), and other head and neck infections (5\%) [6]. In two described cases, the teeth were the etiological factor of the DNM.

In the literature, the molar teeth of mandible are typically originating with the DNM [7]. However, in presented case the upper right first molar was the source of the inflammation which spread thought the fascia to the mediastinum. Complications after the peritonsil abscess where the source of inflammation in second case. Peritonsillar abscess is the most common deep infection of the head and neck in young adults and they happen more frequently in warm moths, with man to female radio 1:1.13 [8]. In this case we had a 50-years-old woman, which was admitted to the ward in the December, with no previous history of upper track inflammation. In $58 \%$ of DNM cases (30\% to $75 \%$ ), is a polymicrobial infection, mainly by gram-positive, such as streptococcus ( $43 \%$ to $62 \%$ ) and anaerobic ( $46 \%$ to $78 \%$ ) bacteria, and less frequently (except in patients with diabetes) by gram-negative enterobacterias, such as Klebsiella (4\% to $8 \%$ ) [5], Prevotella buccae [9]. In all cases we reported the gram-positive streptococcus which comes originate from the oral cavity [10] and the skin. Enterobacteriaceae were also an etiologic factor for mediastinitis after cardiac surgery [11], where there is no direct contact with the oral cavity. The polymicrobial infections could be explained also by the long hospital stay with subsequent patient colonization and a broken skin barrier (Table 3).

In all cases authors reported clinical symptoms which shows the acute spreading inflammations. Tissue necrosis resulting from inflammatory process in combi- nation with inflammation mediators, results in systemic response of the organism, which may lead to patient's systemic infection [12,13]. In case of the possibility of Systemic Inflammatory Response Syndrome (SIRS) development, prothrombin levels, platelets, partial thromboplastic time, D-dimer, decomposition of fibrin products and fibrinogen should be checked continually. These are the examination confirming Disseminated Intravascular Coagulation (DIC), which is connected with systemic infection escalation. In all presented cases substantial growth in D-Dimer and deviations in markers of coagulation has been confirmed. Two from the following symptoms allows diagnosis of Systemic Inflammatory Response Syndrome (SIRS): 1) Body temperature higher than $3^{\circ} \mathrm{C}$, but also lower than $36^{\circ} \mathrm{C}, 2$ ) Heart rate above $90 \mathrm{bpm}, 3)$ Respiration rate above 20 per minute and 4) Increase in leucocytes above $12000 / \mathrm{mm}^{3}$, or lower than $4000 / \mathrm{mm}^{3}$, or more than $10 \%$ of immature forms. In the first and third presented case all of above symptoms appeared, including decrease in body temperature (less than $36^{\circ} \mathrm{C}$ ).

Inflammatory process usually descends to mediastinum and pleural cavities, rarely to the pericardium and abdomen causing cellulitis and abscess in mediastinum. At the later stage can lead to pericarditis, pleural empyema, peritonitis, retroperitoneal space inflammation, sepsis and multiorgan failure [14-17].

Vacuum therapy has been previously used as a treating method in mediastinum inflammation [18]. There is no literature data on their use in isolate odontogenic neck phlegmone. The legitimacy of its use remains a matter of discussion, in the case, despite the use of vacuum therapy; the patient's condition worsened further and required additional treatment within the thoracic surgery unit.

Hyperbaric oxygen therapy is one of the solutions used in the treatment of inflammatory complications, in maxillofacial surgery, orthopedics and surgery, with good results. Therapy allows for expedition of wound healing and inflammation reduction. [11,19] Combination with targeted antibiotics brings expected benefits [20].

\section{Conclusion}

To sum up, dental or surgical treatment postponing of the inflammatory processes causes significant extension in therapy time and in many case requires patient's hospitalization in some cases urgent surgery treatment and wide spectrum of antibiotic therapy. Odontogenic inflammatory disorders and infections which comes from nasopharynx, cause neck and mediastinum bacterial infections, and are life-threatening not only among patients with comorbidities or immunity loss in HIV or immunosuppression, but also, like has been presented in two described cases, among patients without past medical history. In presented cases have not confirmed 
other pathogens than opportunistic bacteria, constantly present in oral cavity. Postponing proper and urgent dental treatment generates social costs (hospitalization, absence from work). Answering the questions asked at the beginning we cannot feel safe postponing dental treatment, delaying surgical treatment, even using wide spectrum of antibiotic therapy. In time of highly developed medicine we still fight with infections complications, such as DNM, where mortality reaches $50 \%$.

\section{References}

1. Diamantis S, Giannakopoulos H, Chou J, Foote J (2011) Descending necrotizing mediastinitis as a complication of odontogenic infection. Int J Surg Case Rep 2: 65-67.

2. Liew YT, Lim EY, Zulkiflee AB, Prepageran N (2017) Severe descending necrotizing mediastinitis: vacuum-assisted dressing did wonder. Gen Thorac Cardiovasc Surg 65: 225-228.

3. Islam A, Oko M (2008) Cervical necrotising fasciitis and descending mediastinitis secondary to unilateral tonsillitis: a case report. J Med Case Rep 2: 368.

4. Hudorovic N, Vucetic B (2008) Infrequent life-threatening complication of descending necrotizing mediastinitis; vertebral artery, internal jugular and subclavian vein rupture. Int J Surg 6: e48-e51.

5. Kocher GJ, Hoksch B, Caversaccio M, Wiegand J, Schmid RA (2012) Diffuse descending necrotizing mediastinitis: surgical therapy and outcome in a single-centre series. Eur J Cardiothorac Surg 42: e66-e72.

6. Prado-Calleros HM, Jiménez-Fuentes E, Jiménez-Escobar I (2016) Descending necrotizing mediastinitis: Systematic review on its treatment in the last 6 years, 75 years after its description. Head Neck 38: e2275-e2283.

7. Kinzer S, Pfeiffer J, Becker S, Ridder GJ (2009) Severe deep neck space infections and mediastinitis of odontogenic origin: clinical relevance and implications for diagnosis and treatment. Acta Otolaryngol 129: 62-70.

8. Freire GSM, Dos Santos JHZ, Rolón PA, Pinheiro GB, Sampaio ALL (2017) Peritonsillar abscess: epidemiology and relationship with climate variations. J Laryngol Otol 131: $627-630$.

9. Lareyre F, Cohen Ch, Declemy S, Raffort J, Quintard H (2017) A Fatal Aortic Arch Rupture Due to Descending
Necrotizing Mediastinitis in a 24-year-old Woman. Vasc Endovascular Surg 51: 408-412.

10. Bahl R, Sandhu S, Singh K, Sahai N, Gupta M (2014) Odontogenic infections: Microbiology and management. Contemp Clin Dent 5: 307-311.

11. Egito JG, Abboud CS, Oliveira AP, Máximo CA, Montenegro CM, et al. (2013) Clinical evolution of mediastinitis in patients undergoing adjuvant hyperbaric oxygen therapy after coronary artery bypass surgery. Einstein (Sao Paulo) 11: $345-349$

12. Delaney P, Rafiq R, Dodd M (2010) Craniocervical necrotising fasciitis--an interesting case with review of the literature. $\mathrm{Br} \mathrm{J}$ Oral Maxillofac Surg 48: e1-e4.

13. McMahon J, Lowe T, Koppel DA (2003) Necrotizing soft tissue infections of the head and neck: case reports and literature review. Oral Surg Oral Med Oral Pathol Oral Radiol Endod 95: 30-37.

14. Rokicki M, Rokicki W, Gawrychowski J, Filipowski M (2006) Is constant, flushing mediastinal drainage is a safe and effective treatment of descending necrotizing mediastinitis? Kardiochirurgia I Torakochirurgia Polska 3: 169-173.

15. Freeman RK, Vallieres E, Varrier EB, Karmy-Jones R, Wood DE (2000) Decending necrotizing mediastinitis: an analysis of the effects of serial surgicaldebridement on patient mortality. J Thorac Cardiovasc Surg 119: 260-267.

16. Stella F, Petrella F (2005) Transsternal, transpericardial approach for acute descending necrotizing mediastinitis. J Thorac Cardiovasc Surg 129: 212-214.

17. Min HK, Choi YS, Shim YM, Sohn YI, Kim J (2004) Descending necrotizing mediastinitis: a minimally invasive approach using video-assisted thoracoscopic surgery. Ann Thorac Surg 77: 306-310.

18. Gallo O, Deganello A, Meccariello G, Spina R, Peris A (2012) Vacuum-assisted closure for managing neck abscesses involving the mediastinum. Laryngoscope 122: 785-788.

19. Hang LW, Lien TC, Wang LS, Wang JH (1997) Hyperbaric oxygen as an adjunctive treatment for descending necrotizing mediastinitis: a case report. Zhonghua Yi Xue Za Zhi (Taipei) 60: 52-56.

20. Kurt T, Vural A, Temiz A, Ozbudak E, Yener AU (2015) Adjunctive Hyperbaric Oxygen Therapy or Alone Antibiotherapy? Methicillin Resistant Staphylococcus aureus Mediastinitis in a Rat Model. Braz J Cardiovasc Surg 30: 538-543. 